\title{
Apoptotic Cell Death Induction Through Pectin, Guar Gum and Zinc Oxide Nanocomposite in A549 Lung Adenocarcinomas
}

\author{
Indu Hira ${ }^{1, \dagger}$, Reena Kumari ${ }^{1, \dagger} \mathbb{D}$, Adesh Kumar Saini ${ }^{2}$ (D), Henok Gullilat ${ }^{1}$, , Vipin Saini ${ }^{3}$ (D), Anil \\ Kumar Sharma $^{2}$ (D), Reena V. Saini ${ }^{2, *}$ (D)
}

1 School of Biotechnology, Faculty of Applied Sciences and Biotechnology, Shoolini University of Biotechnology and Management Sciences, Solan, Himachal Pradesh, 173229, India; isha1982sahotah@gmail.com (I.H.), reena.sharma011@yahoo.com (R.K.), henoksheba@gmail.com (H.G.);

2 Department of Biotechnology, MMEC, Maharishi Markandeshwar (Deemed to be University), Mullana-Ambala, Haryana 133207, India; sainiade@mmumullana.org (A.K.S.), anibiotech18@gmail.com (A.K.S.);

3 Maharishi Markandeshwar University, MMT, Solan, Himachal Pradesh, 173229, India; vipinsaini31@rediffmail.com (V.S.);

$\dagger$ Equal contributing authors;

* Correspondence: reenavohra10@mmumullana.org; reenavohra10@gmail.com (R.V.S.);

Scopus Author ID 35554038200

Received: 5.04.2021; Revised: 10.05.2021; Accepted: 14.05.2021; Published: 10.06.2021

\begin{abstract}
Previously, we reported the immunostimulatory potential of the nanocomposite prepared from biopolymers (Pectin and Guar gum) and zinc oxide (Pec-gg-ZnO) on human peripheral-blood lymphocytes leading to enhanced anti-cancer immunity. The current study aims to describe the direct anti-cancer potential of Pec-gg-ZnO nanocomposite and the relevant mechanism of cell death induction in human lung carcinomas (A549). The cytotoxicity assay revealed the anti-cancer potential of Pec-gg$\mathrm{ZnO}$ nanocomposite towards A549 cells, cervical adenocarcinoma (HeLa), and prostatic small cell carcinoma (PC-3). The $\mathrm{IC}_{50}$ values were $83.67 \pm 0.10 \mu \mathrm{g} / \mathrm{ml}, 87.25 \pm 0.03 \mu \mathrm{g} / \mathrm{ml}$ and $85.95 \pm 0.03 \mu \mathrm{g} / \mathrm{ml}$ for A549, HeLa and PC-3 cells, respectively. The nanocomposite's cancer cells' killing capabilities were significantly higher than pectin and guar gum alone. Hemolysis assay revealed that synthesized Pecgg- $\mathrm{ZnO}$ nanocomposite is biocompatible at $2.5 \mathrm{mg} / \mathrm{ml}$. S phase arrest with enhanced sub-G1 (apoptotic cells) population was examined in A549 cells treated with Pec-gg-ZnO nanocomposite. The nanocomposite caused apoptosis of target cells by inducing mitochondrial depolarisation, reactive oxygen species generation, caspase-3 and Poly (ADP-ribose) polymerase 1 (PARP1) activation resulting in DNA fragmentation. Collectively, the current data revealed that Pec-gg-ZnO nanocomposite is a novel polymer-based anti-cancer agent capable of inducing apoptotic pathways in cancer cells.
\end{abstract}

Keywords: anti-cancer; lung cancer; reactive oxygen species; biopolymers; $\mathrm{ZnO}$.

(C) 2021 by the authors. This article is an open-access article distributed under the terms and conditions of the Creative Commons Attribution (CC BY) license (https://creativecommons.org/licenses/by/4.0/).

\section{Introduction}

It has been estimated that by 2020 , there will be about 12.0 million cancer deaths and about 15.0 million cancer cases will be detected in India alone [1]. The most commonly used treatments are chemotherapy, radiation therapy, and surgery. All these treatments are harmful in which healthy cells are destroyed and are limited due to their side effects [2]. Cancer is the stage when there is a loss of balance between cell death and cell division. Apoptosis is a mechanism to maintain homeostasis, which usually occurs during development and aging. 
During apoptosis, cancerous and virally infected cells are removed, and alterations in apoptotic pathways lead to cancer development and growth [3]. Many genes and proteins are involved in modulating cell death pathways; among them, the caspase family plays a vital role. Mitochondrial membrane depolarization amplifies the apoptotic signals by activation of caspases leading to proteolytic cleavage of cellular targets such as Poly (ADP-ribose) polymerase 1 (PARP1) [4, 5].

Nanotechnology can be described as the restructuring of matter in nanoscale dimensions (i.e., less than $100 \mathrm{~nm}$ ) to yield materials having new properties and functions [68]. Nanocomposites are prepared from nanomaterials by combining one or more components to get each constituent's finest properties $[9,10]$. Polymer nanocomposites are prepared by combining polymers and inorganic/organic fillers at the nanometres scale with several electrical, mechanical, and optical characteristics [11-13]. Natural polymers are preferred over synthetic polymers because of their biocompatibility, biodegradability, ability to be metabolized, stability, extensive surface area and nontoxic $[14,15]$. Several studies on natural biopolymers revealed anti-cancer activities and tumor growth inhibition via polysaccharides by direct toxicity and biocompatibility of the natural polymers [16, 17]. Previously, the synthesis of the pectin, guar gum and zinc oxide (Pec-gg- $\mathrm{ZnO}$ ) nanocomposite has been reported from our lab. The nanocomposite displayed a size range of 50-70 nm, which enhanced the anti-cancer potential of peripheral blood lymphocytes against human cancer cells [18].

Pectin and its modified forms have successfully displayed antitumor activities towards aggressive and recurring tumors [19, 20]. Folic acid-functionalized guar gum nanoparticles loaded with methotrexate have been used for targeted delivery to colon cancer cells [21]. It has been reported that anti-cancer drugs coated with guar gum and eudragit conjugated curcumin exhibited enhanced oral bioavailability and solubility [22]. It has been reported that $\mathrm{ZnO}$ nanoparticles are capable of inducing apoptotic pathways in cancer cells through reactive oxygen species (ROS) production [23-25]. Nano-formulations synthesized by using both inorganic and organic components can induce apoptosis in cancer cells [26, 27].

The detailed method of Pec-gg-ZnO nanocomposite preparation and characterization has been reported earlier [18]. Current studies deal with evaluating the anti-cancer potential of the polymer-based nanocomposite under in vitro conditions. Here, we are describing new anticancer nanocomposite and exploring the cell death mechanism mediated through Pec-gg-ZnO nanocomposite. The apoptotic pathways induced by nanocomposite were studied via examining ROS generation, mitochondrial perturbation, cell cycle alterations and, cleavage of caspase-3 and PARP1 leading to DNA fragmentation in A549 lung adenocarcinomas.

\section{Materials and Methods}

\subsection{Materials.}

Dulbecco's Modified Eagle Medium (DMEM) and Minimum Essential Medium (MEM), Dimethyl Sulphoxide (DMSO), Fetal Bovine Serum (FBS), Phosphate Buffer Saline (PBS), (3-(4, 5- dimethylthiazol-2yl)-2, 5-diphenyltetrazolium bromide (MTT), Propidium Iodide (PI) and Triton X-100 were procured from Himedia (Mumbai, India). Rhodamine123 (Rh123) and 2,7- dichloroflourescin diacetate (DCFDA) were from Sigma Aldrich. 4',6diamidino-2-phenylindole (DAPI) from Thermo fisher scientific. Primary antibodies, purified anti-caspase-3, PARP1 (F-2, sc-8007) and alpha-actinin were purchased from Biolegend and Santa Cruz Biotechnology, respectively. 


\subsection{Cell culture.}

Lung adenocarcinoma (A549), cervical adenocarcinoma (HeLa) and prostate carcinoma (PC-3) cell lines were procured from the National Centre for Cell Sciences, Pune, India. The cells were cultured in DMEM medium containing $10 \%$ heat-inactivated FBS and penicillin/ streptomycin solution (100 units $/ \mathrm{ml}$ and $100 \mathrm{mg} / \mathrm{ml}$ respectively) at $37^{\circ} \mathrm{C}$ in a humidified, $5 \% \mathrm{CO}_{2}$ atmosphere.

\subsection{Preparation and characterization of the nanocomposite.}

The Pec-gg-ZnO nanocomposite was prepared by the nanoprecipitation method. The obtained nanocomposite has a polygonal morphology with a size ranging from 50-70 nm. The nanocomposite preparation and characterization have been published earlier [18].

\subsection{Hemolysis assay.}

The biocompatibility of the biopolymers pectin, guar gum and the nanocomposite was carried out via hemolytic assay. Blood $(10 \mathrm{ml})$ was collected in EDTA-coated vacutainer tubes from healthy human donors after clearance from the Institute Ethics Committee. Blood was centrifuged at $500 \mathrm{x}$ g for $5 \mathrm{~min}$, aspirate plasma. Wash blood cells with $150 \mathrm{mM} \mathrm{NaCl}$ solution, mix and centrifuge at $500 \mathrm{x}$ g for $5 \mathrm{~min}$. Then aspirate supernatant and replace it with PBS. The blood cells were then incubated at $37^{\circ} \mathrm{C}$ for one hour with various concentrations $(0.25$, $0.5,1.0,2.5$ and $5.0 \mathrm{mg} / \mathrm{ml}$ ) of Pec, gg, Pec-gg-ZnO nanocomposite. PBS and 10\% Triton X100 were taken as negative and positive controls, respectively. The treated blood cells were collected by centrifugation. Then absorbance of the supernatant $(100 \mu \mathrm{l})$ was recorded at 541 nm using a microplate reader.

$$
\text { Haemolysis }(\%)=\frac{O D_{\text {test sample }}-O D_{\text {negative control }}}{O D_{\text {positive control }}-O D_{\text {negative control }}} \times 100
$$

where, OD positive control represents absorbance for triton X-100 treated cells; OD negative control represents OD for PBS treated cells and the OD test sample denotes absorbance for treated cells.

\subsection{Cell viability and apoptosis assay.}

Cancer cell lines A549, HeLa and PC-3 (1x10 $)$ were cultured in the 96-well plate and allowed to adhere overnight. Cells were then treated with Pec and gg biopolymers and Pec-gg$\mathrm{ZnO}$ at different concentrations $(25,50,100$ and $200 \mu \mathrm{g} / \mathrm{ml})$ for $24 \mathrm{~h}$, followed by washing with PBS to remove dead. Untreated cells were used as negative control, and Vincristine sulfate $(5 \mu \mathrm{g} / \mathrm{ml})$ treated cells were positive controls. MTT assay was carried out three times in triplicate as described earlier [18]. The percentage of cell death was calculated by using the formula given below:

$$
\% \text { Cell death }=\frac{\mathrm{OD}_{\text {control }}-\mathrm{OD}_{\text {sample }}}{\mathrm{OD}_{\text {control }}} \times 100
$$

where, OD control is the absorbance of untreated cells and the OD sample denotes absorbance of treated cells. 


\subsection{Analysis of cell cycle arrest.}

A549 cancer cells were plated into the 6-well plate $\left(1 \times 10^{6}\right)$ and treated with biopolymers (Pec and gg) and Pec-gg-ZnO at $100 \mu \mathrm{g} / \mathrm{ml}$ for $24 \mathrm{~h}$. The treated cells were washed and trypsinized. The cells were fixed at $4{ }^{\circ} \mathrm{C}$ using $70 \%$ ethanol followed by propidium iodide staining, and the cell cycle perturbations were analyzed by using a Flow Canto II- flow cytometer [28] at a central facility of Post Graduate Institute of Medical Education and Research, Chandigarh, India.

\subsection{Measurement of mitochondrial membrane potential.}

A549 cells $\left(5 \times 10^{4}\right)$ were incubated for 30 min with biopolymers (Pec and gg) and nanocomposite at $100 \mu \mathrm{g} / \mathrm{ml}$. After washing, treated cells were collected by trypsinization. Further, cells were stained with $\mathrm{Rh} 123(25 \mu \mathrm{M})$ in the dark for another $20 \mathrm{~min}$, followed by washing. The mitochondrial membrane depolarization $(\Delta \Psi \mathrm{m})$ was analyzed using a spectrofluorometer having an excitation and emission spectra of 507 and $534 \mathrm{~nm}$, respectively [29]. Vincristine sulfate and Sodium azide were employed as positive controls and untreated cells were used as a negative control.

\subsection{Determination of reactive oxygen species.}

A549 cancer cells $\left(5 \times 10^{4}\right)$ were treated for 30 min with biopolymers (Pec and gg) and Pec-gg-ZnO $(100 \mu \mathrm{g} / \mathrm{ml})$, followed by washing and staining with DCFDA in the dark for another $20 \mathrm{~min}$. ROS generation was determined by a spectrofluorometer using excitation and emission spectra of 485 and $530 \mathrm{~nm}$, respectively. Vincristine sulfate and $\mathrm{H} 2 \mathrm{O} 2$ were worked as positive controls and untreated cells were used as a negative control [30].

\subsection{Analysis of Caspase-3 and PARP 1 activation.}

Caspase-3 activation was detected in untreated A549 cells, vincristine sulphate (positive control), Pec, gg and Pec-gg-ZnO nanocomposite treated cancer cells via western blotting after $24 \mathrm{~h}$ of incubation. Cell pellets $\left(1 \times 10^{6}\right)$ were lysed with RIPA lysing buffer $(1 \mathrm{M}$ Tris $\mathrm{pH}$ 8.0, 0.5 M EDTA, 8.0, $1 \%$ NP-40, $1 \%$ SDS, $150 \mathrm{mM}$ sodium chloride, $0.5 \%$ sodium deoxycholate and protease inhibitor). Cell lysates $(20 \mu \mathrm{g})$ were electrophoresed in $15 \%$ SDS polyacrylamide gel (12\% gel for PARP 1 analysis) and then transferred onto the PVDF membrane. After that the membrane was treated with 5\% condensed milk for $1 \mathrm{~h}$. Following washing, the membrane was treated with an anti-caspase- 3 antibody $(1: 1000)$ or with PARP1 (F-2) antibody $(1: 1000)$ at $4{ }^{\circ} \mathrm{C}$ overnight. Further membranes were treated with Horseradish peroxidase-tagged anti-mouse antibody at 1:5000 dilutions for $1 \mathrm{~h}$. Signals were developed by using an enhanced chemiluminescence detection reagent.

\subsection{Morphological assessment of apoptotic cells by using DAPI staining.}

A549 cells $\left(5 \times 10^{4}\right)$ were treated for $24 \mathrm{~h}$ with biopolymers (Pec and gg) and Pec-gg$\mathrm{ZnO}(100 \mu \mathrm{g} / \mathrm{ml})$ for $24 \mathrm{~h}$. Vincristine sulfate was employed as a positive control. After PBS, washing cells were fixed for 15 min with $4 \%$ paraformaldehyde. Followed by treatment with $0.1 \%$ Triton X-100 for another $15 \mathrm{~min}$ and stained with DAPI in the dark for a further $20 \mathrm{~min}$. The nuclear morphological changes were viewed under a fluorescence microscope (20X) (Olympus 1X 51) after washing the samples with PBS [31]. 


\subsection{DNA fragmentation assay.}

A549 cells were treated with biopolymers (Pec and gg) and Pec-gg-ZnO (100 $\mu \mathrm{g} / \mathrm{ml})$ for $24 \mathrm{~h}$. The lysis buffer ( $50 \mathrm{mM}$ Tris, $20 \mathrm{mM}$ EDTA, $0.5 \%$ Triton X-100) was used to prepare the lysate. The cell lysate was cleared by centrifugation $(11,000 \mathrm{rpm}, 20 \mathrm{~min})$ and the clear supernatant was subjected to $1 \%$ sodium dodecyl sulfate (SDS) and RNase A $(0.1 \mathrm{mg} / \mathrm{ml})$ for 1 $\mathrm{hr}$ at $37^{\circ} \mathrm{C}$, and then proteinase $\mathrm{K}$ treatment was given for $2 \mathrm{~h}$ at $56^{\circ} \mathrm{C}$. For DNA isolation from the supernatant, phenol: chloroform: isoamyl alcohol $(25: 24: 1, \mathrm{v} / \mathrm{v} / \mathrm{v})$ was used and an equal volume of isopropanol was utilized for DNA precipitation at $-20^{\circ} \mathrm{C}$. DNA fragmentation was visualized on $1.8 \%$ agarose gel with an ultraviolet gel documentation system. [32].

\subsection{Statistical analysis.}

The data were statistically analyzed by using Graph Pad Prism version 6.0. The data was significant when $\mathrm{p} \leq 0.05$ and was presented as the average \pm standard deviation.

\section{Results and Discussion}

\subsection{Cytotoxicity assessment by hemolysis assay.}

The initial evaluation of the biocompatibility of biopolymers (Pec and gg) and Pec-gg$\mathrm{ZnO}$ nanocomposite was performed via RBC lysis assay. The results are given in Table 1. Pecgg- ZnO nanocomposite showed overall less hemolysis as compared to Pec and gg. As 5\% hemolysis is acceptable for biomaterials; therefore, Pec-gg- $\mathrm{ZnO}$ nanocomposite can be considered biocompatible nano-formulation up to a concentration of $2.5 \mathrm{mg} / \mathrm{ml}(3.389 \pm 0.07$ $\%$ hemolysis).

Table 1. Hemolytic analysis after treatment with biopolymers and Pec-gg- $\mathrm{ZnO}$ nanocomposite at a concentration range of $0.25 \mathrm{mg} / \mathrm{ml}$ to $5 \mathrm{mg} / \mathrm{ml}$ for $90 \mathrm{~min}$. Data are presented here as mean \pm standard deviation and the experiment was conducted three times.

\begin{tabular}{l|l|l} 
Sample & Concentration $(\mathrm{mg} / \mathrm{ml})$ & $\%$ of Hemolysis \\
\hline Phosphate Buffer Saline (PBS) & & $0.047 \pm 0.00$ \\
\hline Triton X-100 & & 100 \\
\hline \multirow{5}{*}{ Pec } & 0.25 & $3.646 \pm 0.07$ \\
\cline { 2 - 3 } & 0.5 & $3.852 \pm 0.07$ \\
\cline { 2 - 3 } & 1.0 & $3.390 \pm 0.00$ \\
\cline { 2 - 3 } & 2.5 & $4.777 \pm 0.00$ \\
\cline { 2 - 3 } & 5.0 & $5.367 \pm 0.03$ \\
\hline \multirow{5}{*}{ gg } & 0.25 & $2.979 \pm 0.00$ \\
\cline { 2 - 3 } & 0.5 & $3.081 \pm 0.07$ \\
\cline { 2 - 3 } & 1.0 & $4.674 \pm 0.00$ \\
\cline { 2 - 3 } & 2.5 & $3.878 \pm 0.10$ \\
\cline { 2 - 3 } & 5.0 & $5.187 \pm 0.07$ \\
\hline \multirow{5}{*}{ Pec-gg-ZnO } & 0.25 & $2.028 \pm 0.03$ \\
\cline { 2 - 3 } & 0.5 & $2.824 \pm 0.03$ \\
\cline { 2 - 3 } & 1.0 & $3.389 \pm 0.07$ \\
\cline { 2 - 3 } & 2.5 & $5.084 \pm 0.07$ \\
\cline { 2 - 3 } & 5.0 &
\end{tabular}

\subsection{Pec-gg-ZnO characterization by TEM.}

As described earlier, the size of nanocomposite ranges from 50-70 nm [18]. TEM images showed Pec-gg-ZnO nanocomposite with $\mathrm{ZnO}$ embedded in the biopolymer matrix (Figure 1). 


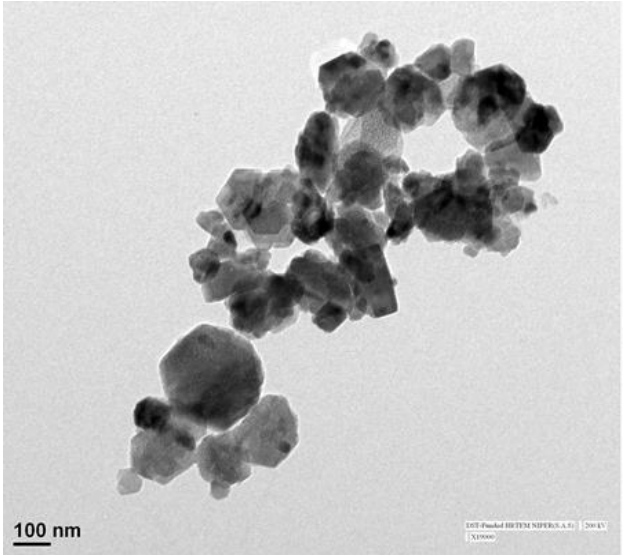

Figure 1. TEM analysis of Pec-gg- $\mathrm{ZnO}$ showing $\mathrm{ZnO}$ (black spots) embedded in the Pec and gg matrices (grey part).

\subsection{Cytotoxicity of Pec-gg-ZnO towards cancer cells.}

The MTT assay revealed the anti-cancer potential of nanocomposite enhanced with an increase in concentrations $(25-200 \mu \mathrm{g} / \mathrm{ml}$ ) (Figure 2a, b and c). The Pec-gg-ZnO exhibited enhanced cancer cell killing as compared to biopolymers (pec and gg) used alone. IC50 values revealed that Pec-gg-ZnO exhibited similar bioactivity towards three cell lines (A549, HeLa and PC-3) used, whereas biopolymers, pec and gg showed very high IC50 values towards HeLa cells (Table 2). The IC50 values towards A549 and HeLa were undefinable after treatment with pec and gg. Microscopic examination also revealed decreased cell number and altered morphology with the increase in the concentration of the Pec-gg- $\mathrm{ZnO}$ (Figure 3).

$\mathbf{a}$
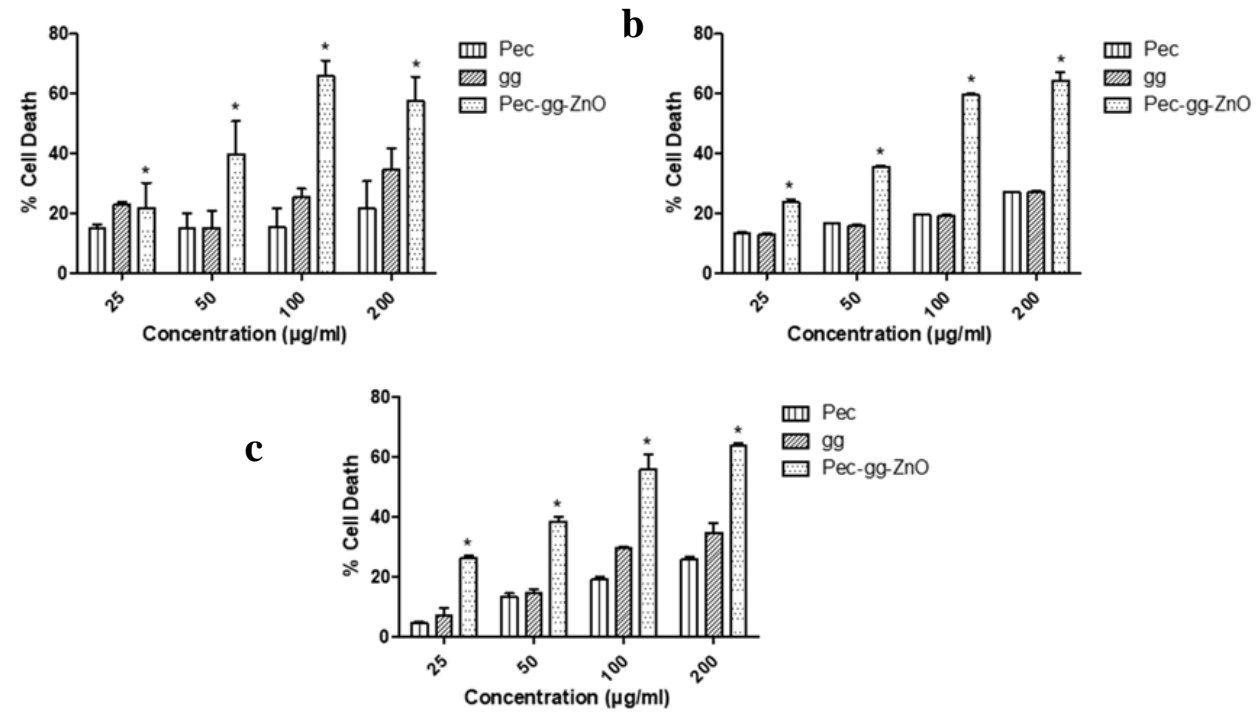

Figure 2. Anti-cancer activity of the biopolymers and Pec-gg-ZnO nanocomposite $(25-200 \mu \mathrm{g} / \mathrm{ml})$ after $24 \mathrm{~h}$ of exposure on (a) A549 (b) HeLa and (c) PC-3 cancer cells. Data were presented as Mean \pm SEM and results were significant as $\mathrm{p}$ values is $\leq 0.05$ denoted by asterisk $(*)$.

Table 2. Comparative analysis of $\mathrm{IC}_{50}$ values for A549, HeLa, and PC-3 cells treated with biopolymers (Pec and

\begin{tabular}{c|c|c|c}
\multirow{2}{*}{ Cancer cell line } & \multicolumn{3}{|c}{ gg) and Pec-gg-ZnO nanocomposite. } \\
\cline { 2 - 4 } & Pec & IC $\mathbf{5 0}(\boldsymbol{\mu g} / \mathbf{m l})$ & Pec-gg-ZnO \\
\hline A549 & N.A. & N.A. & $83.67 \pm 0.10$ \\
\hline PC-3 & N.A. & N.A. & $87.25 \pm 0.03$ \\
\hline HeLa & $781.7 \pm 0.09$ & $374.2 \pm 0.08$ & $85.95 \pm 0.03$
\end{tabular}




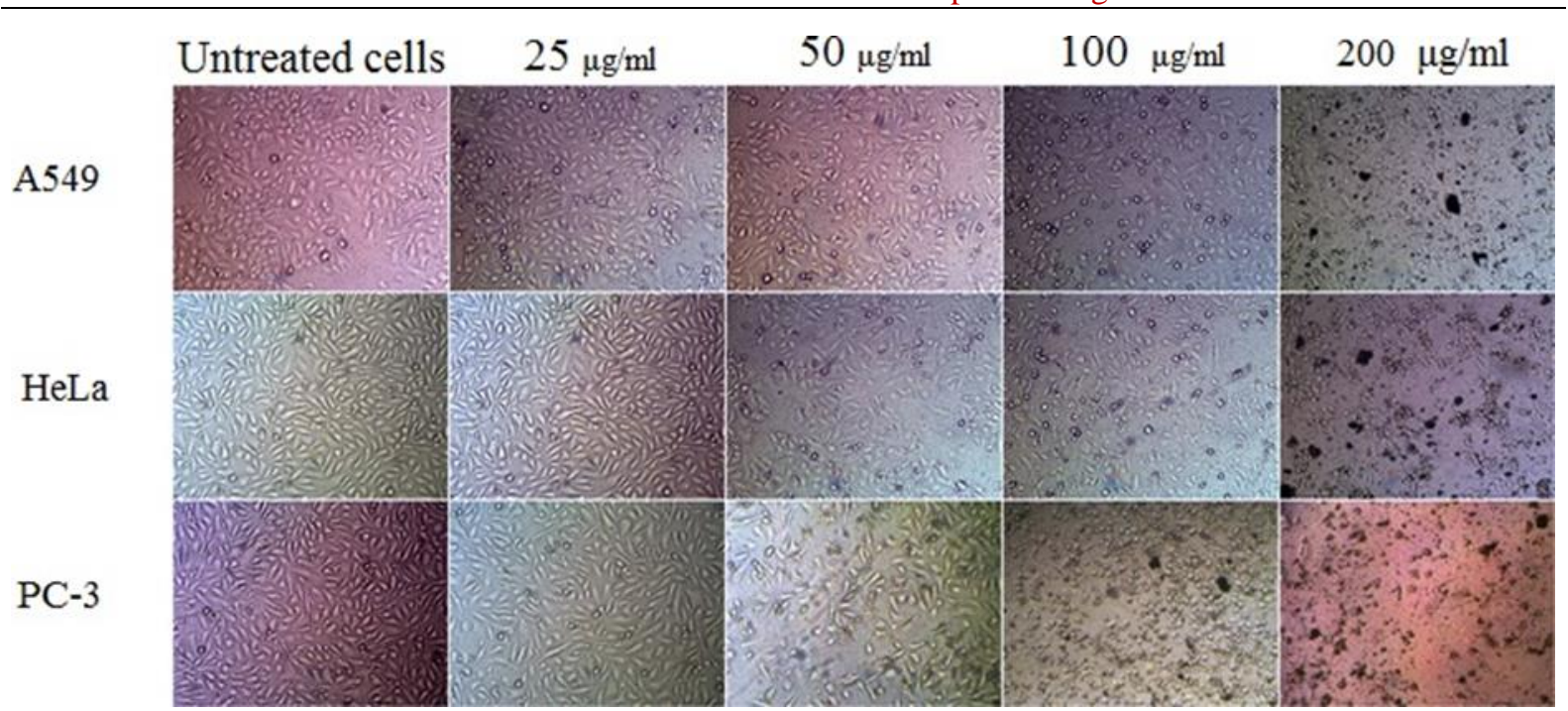

Figure 3. Microscopic images of different cell lines (A549, HeLa and PC-3 cells) incubated with Pec-gg-ZnO at various concentrations for $24 \mathrm{~h}$.

\subsection{Analysis of cell cycle arrest.}

Figure 4, shows the cell cycle analysis on A549 ling carcinomas after incubation with biopolymers (Pec and gg) and Pec-gg-ZnO nanocomposite. The results showed cell cycle arrest in S-phase following treatment with biopolymers and Pec-gg-ZnO nanocomposite. Furthermore, Pec-gg-ZnO nanocomposite pre-treated A549 cells displayed significantly (10.35 \pm 2.25 ) enhanced apoptosis (Sub-G1 phase) as compared to negative control (1.75 \pm 0.05$)$. Pec and gg-treated A549 cells exhibited a small increase in Sub-G1 stage cells, $1.90 \pm 0.08 \%$ and $2.35 \pm 1.55 \%$, respectively.
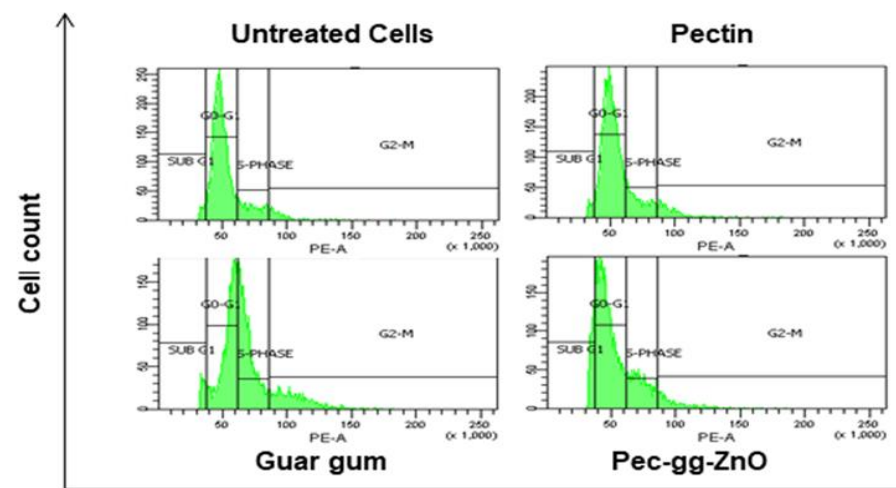

Propidium lodide Flourescence

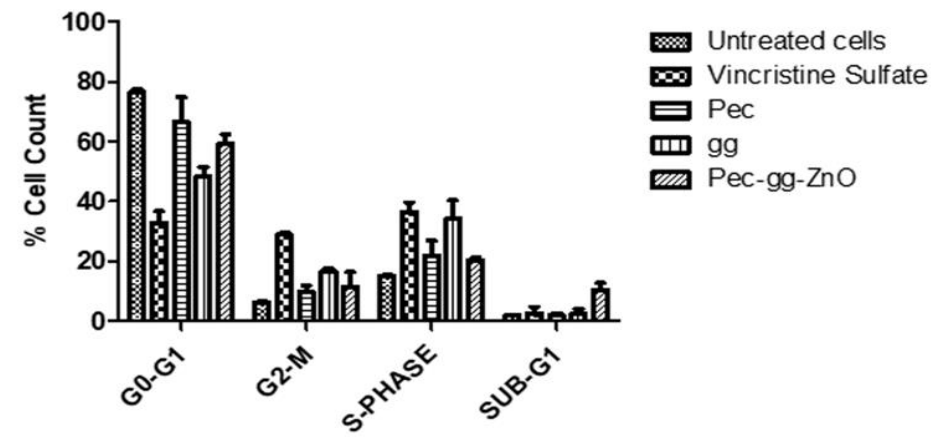

Figure 4. Cell cycle phases of A549 cells incubated for $24 \mathrm{~h}$ with biopolymers (Pec and gg) and nanocomposite $(100 \mu \mathrm{g} / \mathrm{ml})$. Data were presented as Mean \pm S.E.M. of three different experiments and results were significant as $\mathrm{p}$ value is $\leq 0.001$. 


\subsection{Determination of mitochondrial membrane potential.}

Mitochondrial depolarization was evaluated in A549 cancer cells. The results revealed a significant mitochondrial membrane perturbation (Figure 5) when cells were treated with Pec-gg-ZnO nanocomposite compared to other treatments given to the A549 cells. As given in Figure 5, the cells incubated with Pec or gg depicted no change in mitochondrial depolarization after 30 minutes of incubation.

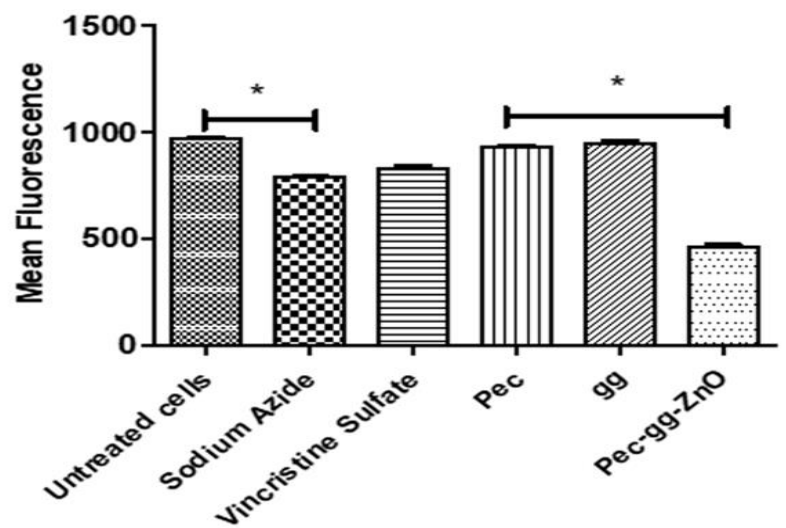

Figure 5. Mitochondrial depolarization was analyzed after $30 \mathrm{~min}$. exposure of A549 cells to test samples (100 $\mu \mathrm{g} / \mathrm{ml})$ and controls. The results were shown as Mean $\pm \operatorname{SEM}(\mathrm{n}=3$ and $* \mathrm{p} \leq 0.05)$.

\subsection{Intracellular reactive oxygen species generation.}

The generation of ROS by biopolymers (Pec and gg) and Pec-gg-ZnO nanocomposite was assessed by using DCFDA, which detects intracellular H2O2. Pre-treatment with Pec-gg$\mathrm{ZnO}$ nanocomposite caused a 12-fold increase in ROS levels (DCF fluorescence), whereas Pec and gg treated cells displayed 2-fold and 1.8-fold increase in DCF fluorescence, respectively. $\mathrm{H}_{2} \mathrm{O}_{2}$ treated cells were used as positive controls (Figure 6).

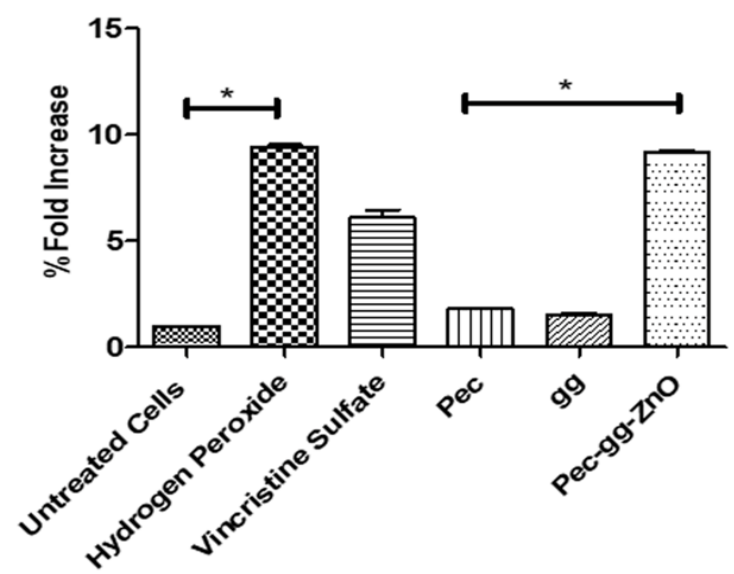

Figure 6. ROS generation was analyzed after 30 minutes of exposure of A549 cells to test samples $(100 \mu \mathrm{g} / \mathrm{ml})$ and control $(n=3)$ and expressed here as fold increase in fluorescence. The data was shown here as Mean \pm SEM

$$
(* \mathrm{p} \leq 0.05) \text {. }
$$

\subsection{Caspase-3 and PARPI activation.}

To evaluate the apoptotic pathway activated by Pec-gg-ZnO nanocomposite, cleaved caspases-3 and PARP1 proteins were analyzed. The data depicted activated caspase- 3 in Pecgg- $\mathrm{ZnO}$ treated A549 cells, but Pec and gg did not affect caspase-3 cleavage (Figure 7). Following nanocomposite treatment, the PARP1 cleaved fragment of $24 \mathrm{kDa}$ was detected in 
A549 cell lysate, which suggested Pec-gg-ZnO induce cancer cells death by caspase-3 and PARP1 stimulation. Caspase-3 and PARP1 mediated cancer cell death was also evident in vincristine sulfate (positive control) treated cells but not in Pec and gg treated cells (Figure 7).

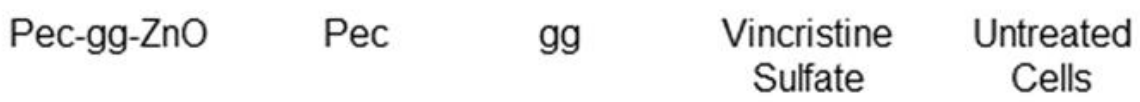

Alpha-actinine

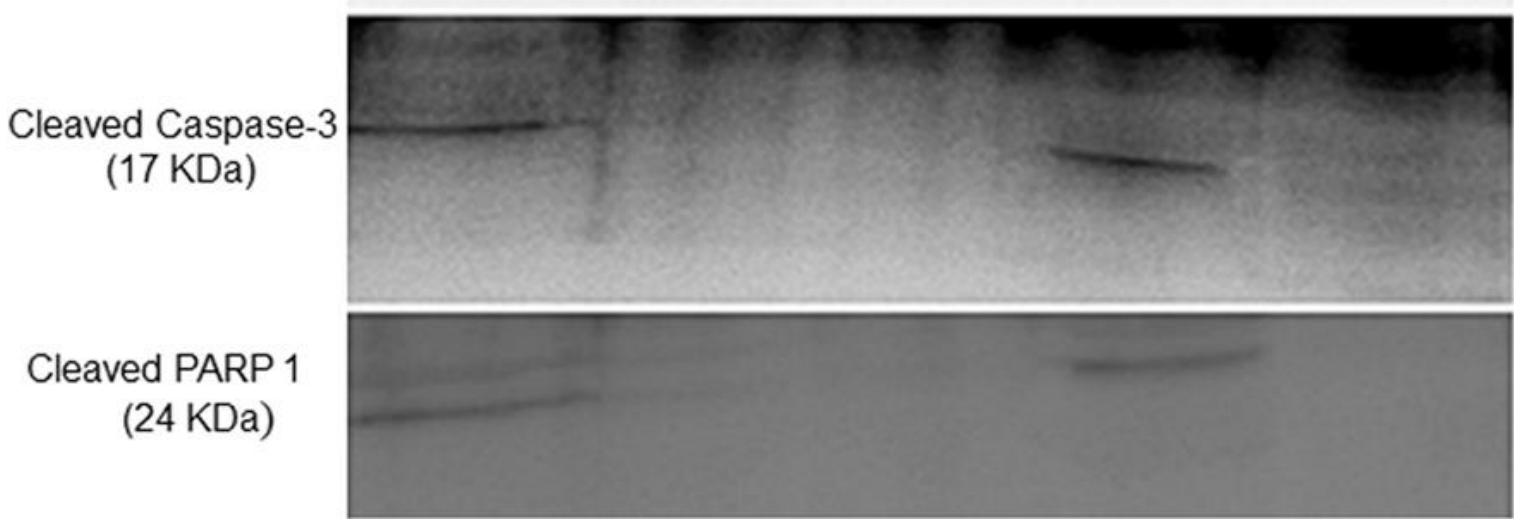

Figure 7. Cleaved caspase- 3 and PARP 1 in the cellular lysate of A549 cells treated with Pec, gg and Pec-gg$\mathrm{ZnO}$ nanocomposite. Vincristine sulfate treated cells were used as positive and untreated cells as a negative control. The experiment was performed three times.

\subsection{Morphological assessment of apoptotic cells by DAPI staining.}

The morphology of apoptotic cells is characterized by cell shrinkage, nuclear blabbing, DNA fragmentation and chromatin condensation. To check apoptosis in A549 cells were treated with biopolymers (Pec and gg) and Pec-gg-ZnO $(100 \mu \mathrm{g} / \mathrm{ml})$ nanocomposite followed by DAPI staining. Untreated cells, Pec and gg treated cells showed normal nuclei, whereas the cells treated with Pec-gg-ZnO nanocomposite displayed condensed and fragmented nuclei which are characteristics of apoptosis (Figure 8).

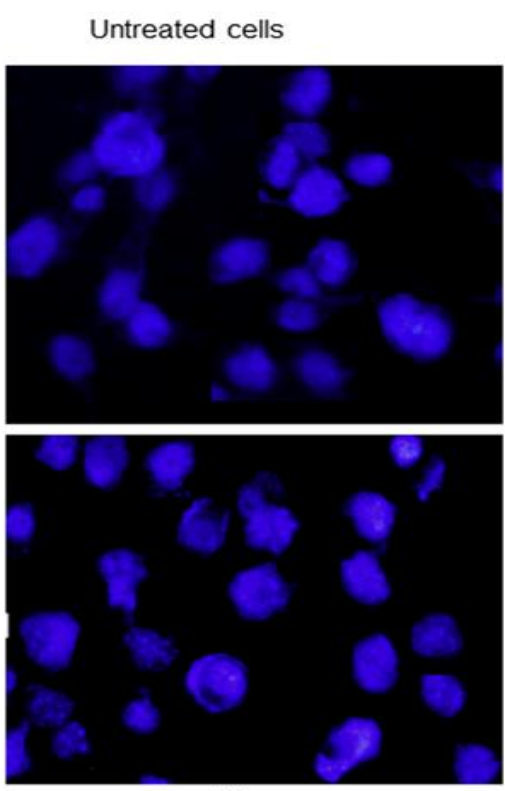

gg
Vincristine Sulphate
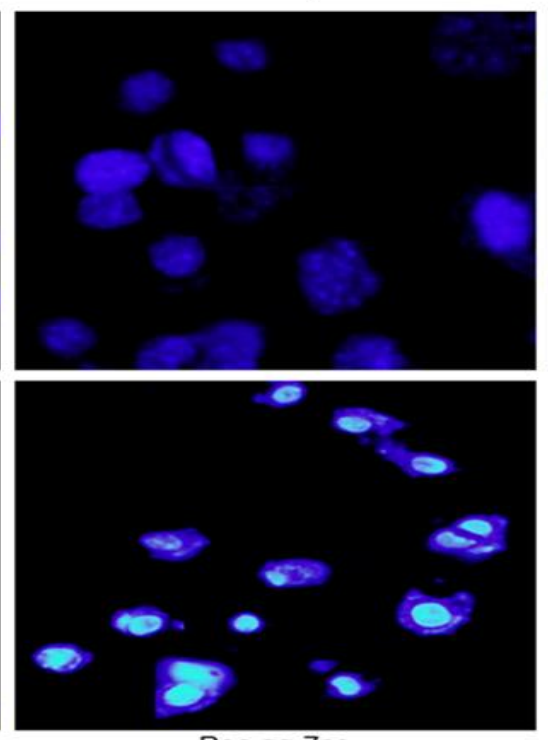

Pec-gg-Zno
Pec

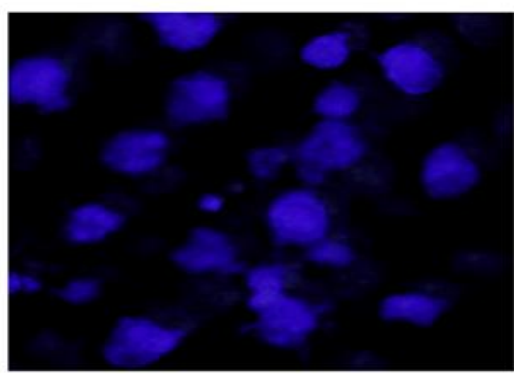

Figure 8. Fluorescent microscopic images of DAPI staining. 


\subsection{DNA fragmentation analysis.}

Cleavage of genomic DNA into a ladder of small fragments is one of the hallmarks of apoptosis [33]. Pec-gg-ZnO treated A549 cells displayed a typical DNA fragmentation following $24 \mathrm{~h}$ of incubation, whereas Pec and gg treated cells did not display any DNA cleavage (Figure 9).

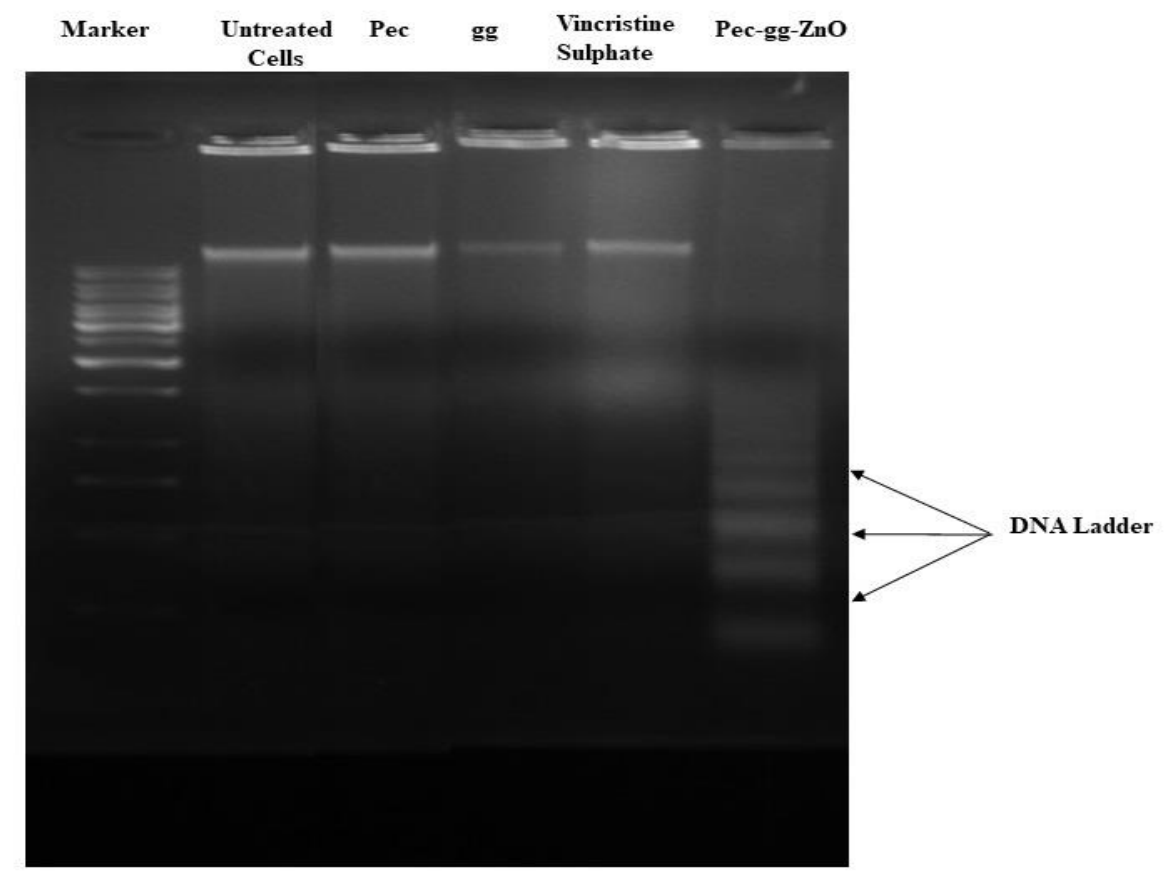

Figure 9. DNA fragmentation analysis for apoptosis detection. Pec-gg-ZnO $(100 \mu \mathrm{g} / \mathrm{ml})$ treated cells showed typical DNA fragments.

\section{Discussion}

It has been reported earlier that Pectin extracts inhibit hypotonicity-induced lysis of erythrocyte membrane, thereby exhibiting membrane stabilization effect and were biocompatible [34]. Similarly, it has been shown that guar gum displayed negligible toxicity against the human erythrocyte, revealing biocompatibility of the guar gum [35]. The data here also revealed the biocompatibility of biopolymers (Pec and $\mathrm{gg}$ ) and the nanocomposite at 2.5 $\mathrm{mg} / \mathrm{ml}$, which suggests minimal toxicity of nanocomposite even at higher concentrations.

Pec-gg-ZnO nanocomposite exhibited anti-cancer activity towards A549, HeLa and PC-3 cells. Earlier, heat-modified Citrus pectin has been shown to induce cell death in HepG2 and A549 cells through the process of autophagy [36]. Guar seeds extract been shown to possess anti-cancer potential towards PC-3 and human colorectal carcinomas (HCT116 and CACO-2) [37]. The enhanced cancer cell death via Pec-gg-ZnO suggested that the interaction between Pec, gg and $\mathrm{ZnO}$ at the nano level has enabled the Pec-gg-ZnO formulation mediated cancer cell death under in vitro conditions.

One of the hallmarks of cancer is uncontrolled cell division [38] and inhibition of the cell cycle progression is considered as a practical approach to eradicate cancer cells [39]. Cell cycle analysis showed that Pec-gg-ZnO nanocomposite induced $\mathrm{S}$ phase arrest leading to apoptotic of cancer cells. Mitochondrial dysfunction has been shown to play a central role in apoptotic induction [40, 41]. Similarly, elevation in ROS levels causes cancer cell death selectively without affecting normal cells. N-ethyl-4-(2-isothiocyanatoethyl) benzamide (LBL21) is a ROS-modulating agent which resulted in the anti-cancer activity of LBL21 
towards stem-like cancer cells and mice bearing A549 lung cancer xenografts [42]. The current data indicated that the Pec-gg-ZnO nanocomposite caused mitochondrial damage and ROSmediated killing of cancer cells [43]. Earlier studies have shown that a minor increase in ROS can induce cell proliferation, whereas a significant increase in ROS enhances apoptosis in prostate cancer cells [44]. ZnO NPs have been shown to enhance intracellular ROS levels up to $30-40 \%$, which led to apoptosis induction in human pulmonary adenocarcinoma cells [45]. Pec-gg-ZnO has been shown to activate caspase-3 and PARP1. The downstream activation of various cytoplasmic or nuclear proteins, including PARP, is initiated by activating effector caspases such as caspase-3 [46]. PARP1 is one of the well-known cellular substrates of caspases, which is a distinct feature of apoptosis. In apoptosis, PARP1 (116 kDa) is cleaved by activated caspases-3 into two fragments of $89 \mathrm{kDa}$ and $24 \mathrm{kDa}$, resulting in the activation of its catalytic activity [47].

\section{Conclusions}

The current study deals with the evaluation of the Pec-gg-ZnO nanocomposite as a novel anti-cancer agent. The hemolytic assay confirmed biocompatibility of the nanocomposite and the cytotoxicity assay revealed the promising anti-cancer activity of Pec-gg- $\mathrm{ZnO}$ nanocomposite against A549, Hela and PC-3 cancer cells. Cell cycle analysis revealed S-phase arrest and apoptotic induction in A549 cells treated with Pec-gg-ZnO nanocomposite. Further, mitochondrial depolarization, ROS generation and activation of caspase-3 and PARP1 confirmed the commencement of the apoptotic process by Pec-gg-ZnO nanocomposite. Taken together, the data suggest that Pec-gg-ZnO nanocomposite can be utilized as an anti-cancer therapeutic.

\section{Funding}

The authors are thankful to Maharishi Markandeshwar (Deemed to be University) and Centre of Research on Himalayan Sustainability and Development, Shoolini University, for providing facilities and financial support.

\section{Acknowledgments}

This research has no acknowledgments.

\section{Conflict of interest}

The author declares no conflict of interest in publishing this manuscript.

\section{References}

1. Mallath, M.K.; Taylor, D.G.; Badwe, R.A.; Rath, G.K.; Shanta, V.; Pramesh, C.S.; Digumarti, R.; Sebastian, P.; Borthakur, B.B.; Kalwar, A.; Kapoor, S.; Kumar, S.; Gill, J. G.; Kuriakose, Malhotra, H.; Sharma, S.C.; Shukla, S.; Viswanath, L.; Chacko, R.T.; Pautu, J.L.; Reddy, K.S.; Sharma, K.S.; Purushotham, A.D.; Sullivan, R. The growing burden of cancer in India: epidemiology and social context. Lancet Oncol. 2014, 15, e205-e212, https://doi.org/10.1016/S1470-2045(14)70115-9.

2. Vaid, P.; Raizada, P.; Saini, A.K.; Saini R.V. Biogenic silver, gold and copper nanoparticles - A sustainable green chemistry approach for cancer therapy. Sustain. Chem. Pharm. 2020, 16, 100247, https://doi.org/10.1016/j.scp.2020.100247. 
3. Baig, S.; Seevasant, I.; Mohamad, J.; Mukheem, A.; Huri, H.Z.; Kamarul, T. Potential of apoptotic pathway targeted cancer therapeutic research: Where do we stand? Cell Death Dis. 2016, 7, e205, https://doi.org/10.1038/cddis.2015.275.

4. Tang, D.; Kang, R.; Berghe, T.V.; Vandenabeele, P.; Kroemer, G. The molecular machinery of regulated cell death. Cell Res. 2019, 29, 347-364, https://doi.org/10.1038/s41422-019-0164-5.

5. Decker, P.; Muller, S. Modulating poly (ADP-ribose) polymerase activity: potential for the prevention and therapy of pathogenic situations involving DNA damage and oxidative stress. Curr. Pharm. Biotechnol. 2002, 3, 275-283, https://doi.org/10.2174/1389201023378265.

6. Ayodele, A.T.; Valizadeh, A.; Adabi, M.; Esnaashari, S.S.; Madani, F.; Khosravani, M.; Adabi, M. Ultrasound nanobubbles and their applications as theranostic agents in cancer therapy: a review. Biointerface Res. Appl. Chem. 2017, 7, 2253 - 2262.

7. Zahin, N.; Anwar, R.; Tewari, D.; Kabir, M.T.; Sajid, A.; Mathew, B.; Uddin, M. S.; Aleya, L.; Abdel-Daim, M. M. Nanoparticles and its biomedical applications in health and diseases: special focus on drug delivery. Environ. Sci. Pollut. Res. 2020, 27, 19151-19168, https://doi.org/10.1007/s11356-019-05211-0.

8. Sharma, G.; Naushad, M.; Thakur, B.; Kumar, A.; Negi, P.; Saini, R.; Chahal, A.; Kumar, A.; Stadler, F.J.; Aqil, U.M.H. Sodium Dodecyl Sulphate-Supported Nanocomposite as Drug Carrier System for Controlled Delivery of Ondansetron. Int. J. Environ. Res. Public Health 2018, 15, 414, https://doi.org/10.3390/ijerph15030414.

9. Rad, Z.P.; Mokhtari, J.; Abbasi, M. Preparation and characterization of Calendula officinalis-loaded PCL/ gum arabic nanocomposite scaffolds for wound healing applications. Iran Polym. J. 2018, 28, 51-63, https://doi.org/10.1007/s13726-018-0674-x.

10. Gollapudi, V.R; Mallavarapu, U.; Seetha, J.; Duddela, V.; Amara, V.R.; Vatti, C.S; Anumakonda, V. In situ generation of antibacterial bimetallic silver and copper nanocomposites using Tinospora cordifolia leaf extract as bio reductant. Biointerface Res. Appl. Chem. 2020, 10, 5569-5574, https://doi.org/10.33263/BRIAC103.569574.

11. Feldman, D. Polymers and Polymer Nanocomposites for Cancer Therapy. Appl. sci. 2019, 9, 3899, https://doi.org/10.3390/app9183899.

12. Fu, S.; Sun, Z.; Huang, P.; Li, Y.; Hu, N. Some basic aspects of polymer nanocomposites: A critical review. Nano Materials Science 2019, 1, 2-30, https://doi.org/10.1016/j.nanoms.2019.02.006.

13. Urbano, B.F.; Mella, C.; Vera, M. Smart polymer nanocomposites: recent advances and perspectives. J. Chil. Chem. Soc. 2020, 65, 4973-4981, https://www.jcchems.com/index.php/JCCHEMS/article/view/1559.

14. Wong, K.H.; Lu, A.; Chen, X.; Yang, Z. Natural Ingredient-Based Polymeric Nanoparticles for Cancer Treatment. Molecules 2020, 25, 3620, https://doi.org/10.3390/molecules25163620.

15. Zare, E.N.; Makvandi, P.; Borzacchiello, A.; Tay, F.R.; Ashtari, B.; Padil, V.V.T. Antimicrobial gum biobased nanocomposites and their industrial and biomedical applications. Chem. Commun. 2019, 55, 1487114885, https://doi.org/10.1039/c9cc08207g.

16. Rapa, M.; Stefan, L.M.; Preda, P.; Darie-Nita, R.N.; Gaspar-Pintiliescu, A.; Seciu, A.M.; Vasile, C.; Matei, E.; Predescu, A.M. Effect of hydrolyzed collagen on thermal, mechanical and biological properties of poly (lactic acid) bionanocomposites. Iran Polym. J. 2019, 28, 271-282, https://doi.org/10.1007/s13726-01900694-7.

17. Thakur, S.; Saini, R.V.; Singh, P.; Raizada, P.; Thakur, V.K.; Saini, A.K. Nanoparticles as an emerging tool to alter the gene expression: Preparation and conjugation methods. Mater. Today Chem. 2020, 17, 100295, https://doi.org/10.1016/j.mtchem.2020.100295.

18. Hira, I.; Kumar, A.; Kumari, R.; Saini, A.K.; Saini, R.V. Pectin-guar gum-zinc oxide nanocomposite enhances human lymphocytes cytotoxicity towards lung and breast carcinomas. Mater. Sci. Eng. C 2018, 90, 494-503, https://doi.org/10.1016/j.msec.2018.04.085.

19. Zaitseva, O.; Khudyakov, A.; Sergushkina, M.; Solomina, O.; Polezhaeva, T. Pectins as a universal medicine. Fitoterapia 2020, 146, 104676, https://doi.org/10.1016/j.fitote.2020.104676.

20. Leclere, L.; Cutsem, P.V.; Michiels, C. Anti-cancer activities of pH- or heat-modified pectin. Front. Pharmacol. 2013, 4, 128, https://doi.org/10.3389/fphar.2013.00128.

21. Sharma, M.; Malik, R.; Verma, A.; Dwivedi, P.; Banoth, G.S.; Pandey, N.; Sarkar, J.; Mishra, P.R.; Dwivedi, A.K. Folic acid conjugated guar gum nanoparticles for targeting methotrexate to colon cancer. J. Biomed. Nanotechnol. 2013, 9, 96-106, https://doi.org/10.1166/jbn.2013.1474. 
22. Kumar, V.S.; John, R.; Sabitha, M. Guargum and eudragit coated curcumin liquisolid tablets for colon specific drug delivery. Int. J. Biol. Macromol. 2018, 110, 318-327, https://doi.org/10.1016/j.ijbiomac.2018.01.082.

23. Srikanth Vallabani, N.V.; Sengupta, S.; Shukla, R.K.; Kumar, A. ZnO nanoparticles-associated mitochondrial stress-induced apoptosis and G2/M arrest in HaCaT cells: a mechanistic approach, Mutagenesis 2019, 34, 265-277, https://doi.org/10.1093/mutage/gez017.

24. Wiesmann, N.; Tremel, W.; Brieger, J. Zinc oxide nanoparticles for therapeutic purposes in cancer medicine. J. Mater. Chem. B. 2020, 8, 4973-4989, https://doi.org/10.1039/D0TB00739K.

25. Wang, S.W.; Lee, C.H.; Lin, M.S.; Chi, C.W.; Chen, Y.J.; Wang, G.S.; Liao, K.W.; Chiu, L.P.; Wu, S.H.; Huang, D.M.; Chen, L.; Shen, Y.S. ZnO nanoparticles induced caspase-dependent apoptosis in gingival squamous cell carcinoma through mitochondrial dysfunction and p70S6K signaling pathway. Int. J. Mol. Sci. 2020, 21, 1612-1628, https://doi.org/10.3390/ijms21051612.

26. Wei, Q. Y.; Xu, Y. M.; Lau, A.T.Y. Recent progress of nanocarrier-based therapy for solid malignancies. Cancers 2020, 12, 2783, https://doi.org/10.3390/cancers12102783.

27. Fonseca, A.C.; Serra, A.C.; Coelho, J.F.J. Bioabsorbable polymers in cancer therapy: latest developments. The EPMA J. 2015, 6, 1-18, https://doi.org/10.1186/s13167-015-0045-z.

28. Girek, M.; Kłosiński, K.; Grobelski, B.; Pizzimenti, S.; Cucci, M.A.; Daga, M.; Barrera, G.; Pasieka, Z.; Czarnecka, K.; Szymański, P. Novel tetrahydroacridine derivatives with iodobenzoic moieties induce G0/G1 cell cycle arrest and apoptosis in A549 non-small lung cancer and HT-29 colorectal cancer cells. Mol. Cell. Biochem. 2019, 460, 123-150, https://doi.org/10.1007/s11010-019-03576-X.

29. Tian, S,; Saravanan, K.; Mothana, R.A.; Ramachandran, G.; Rajivgandhi, G.; Manoharan, N. Anti-cancer activity of biosynthesized silver nanoparticles using Avicennia marina against A549 lung cancer cells through ROS/mitochondrial damages. SaudiJ. Biol. Sci. 2020, 27, 3018-3024, https://doi.org/10.1016/j.sjbs.2020.08.029.

30. Wu, D.; Yotnda, P. Production and detection of reactive oxygen species (ROS) in cancers. J. Vis. Exp. 2011, 57, e3357, https://doi.org/10.3791/3357.

31. Kumari, R.; Saini, A.K.; Chhillar, A.K.; Saini, V.; Saini, R.V. Antitumor effect of bio-fabricated silver nanoparticles towards ehrlich ascites carcinoma. Biointerface Res. Appl. Chem. 2021, 11, 12958-12972, https://doi.org/10.33263/BRIAC115.1295812972.

32. Kumari, R.; Saini, A.K.; Kumar, A.; Saini, R.V. Apoptosis induction in lung and prostate cancer cells through silver nanoparticles synthesized from Pinus roxburghii bioactive fraction. J. Biol. Inorg. Chem. 2020, 25, 2337, https://doi.org/10.1007/s00775-019-01729-3.

33. Peitsch, M.C.; Muller, C.; Tschopp, J. DNA fragmentation during apoptosis is caused by frequent singlestrand cuts. Nucleic Acids Res. 1993, 21, 4206-4209, https://doi.org/10.1093/nar/21.18.4206.

34. Sood, N.; Mathu, A. Evaluation of pharmacological activities of pectin extracted from apple and citrus pomace. Biolife 2014, 2, 1203-1217.

35. Bukhari, S.A.; Shahid, M.; Anjum, F.; Rasheed, A.; Munir, H. Purification, fragmentation and characterization of gum from Cyamopsis tetragonolobus to enhance its nutraceutical attributes. Pak. J. agri. sci. 2014, 51, 1059-1068.

36. Leclere, L.; Fransolet, M.; Cote, F.; Cambier, P.; Arnould, T.; Cutsem, P.V.; Michiels, C. Heat-modified citrus pectin induces apoptosis-like cell death and autophagy in HepG2 and A549 cancer cells. PLOS One 2015, 10, e0115831, https://doi.org/10.1371/journal.pone.0115831.

37. Badr, S.E.; Abdelfattah, M.S.; El-Sayed, S.H.; El-Aziz, A.S.A.; Sakr, D.M. Evaluation of anti-cancer, antimycoplasmal activities and chemical composition of Guar (Cyamopsis tetragonoloba) seeds extract. Res. J. Pharm. Biol. Chem. Sci. 2014, 5, 414-423.

38. Li, X.; Xu, P.; Wang, C.; Xu, N.; Xu, A.; Xu, Y.; Sadahira, T.; Araki, M.; Wada, K.; Matsuura, E.; Watanabe, M.; Zheng, J.; Sun, P.; Huang, P.; Nasy, Y.; Liu, C. Synergistic effects of the immune check point inhibitor CTLA-4 combined with the growth inhibitor lycorine in a mouse model of renal cell carcinoma. Oncotarget 2017, 8, 21177- 21186, https://doi.org/10.18632/oncotarget.15505.

39. Otto, T.; Sicinski, P. Cell cycle proteins as promising targets in cancer therapy. Nat. Rev. Cancer. 2017, 17, 93-115, https://doi.org/10.1038/nrc.2016.138.

40. Desagher, S.; Martinou, J-C. Mitochondria as the central control point of apoptosis. Trends Cell Biol. 2000, 10, 369-377, https://doi.org/10.1016/S0962-8924(00)01803-1.

41. Ly, J.D.; Grubb, D.R.; Lawen, A. The mitochondrial membrane potential $(\Delta \psi \mathrm{m})$ in apoptosis; an update. Apoptosis 2003, 8, 115-128, https://doi.org/10.1023/A:1022945107762. 
42. Wang, J.; Luo, B.; Li, X.; Lu, W.; Yang, J.; Hu, Y.; Huang, P.; Wen, S. Inhibition of cancer growth in vitro and in vivo by a novel ROS-modulating agent with ability to eliminate stem-like cancer cells. Cell Death Dis. 2017, 8, e2887, https://doi.org/10.1038/cddis.2017.272.

43. Trachootham, D.; Alexandre, J.; Huang, P. Targeting cancer cells by ROS-mediated mechanisms: a radical therapeutic approach? Nat. Rev. Drug Discov. 2009, 8, 579-591, https://doi.org/10.1038/nrd2803.

44. Das, T.P.; Suman, S.; Damodaran, C. Induction of reactive oxygen species generation inhibits epithelialmesenchymal transition and promotes growth arrest in prostate cancer. Mol. Carcinog. 2014, 53, 537-547, https://doi.org/10.1002/mc.22014.

45. Wang, C.; Hu, X.; Gao, Y.; Ji, Y. ZnO nanoparticles treatment induces apoptosis by increasing intracellular ROS levels in LTEP-a-2 cells. Biomed. Res. Int. 2015, 2015, 423287, https://doi.org/10.1155/2015/423287.

46. Huppertz, B.; Frank, H-G.; Kaufmann, P. The apoptosis cascade-morphological and immunohistochemical methods for its visualization. Anat. Embryol. (Berl). 1999, 200, 1-18, https://doi.org/10.1007/s004290050254.

47. Chaitanya, G.V.; Steven, A.J.; Babu, P.P. PARP-1 cleavage fragments: signatures of cell-death proteases in neurodegeneration. Cell Commun. Signal 2010, 8, 31, https://doi.org/10.1186/1478-811X-8-31. 